\title{
Thermal conductivity and bending strength of SiC composites reinforced by pitch-based carbon fibers
}

\author{
Liyang $\mathrm{CAO}^{a}$, Yongsheng $\mathrm{LIU}^{a, *}$, Yunhai ZHANG ${ }^{a}$, Yejie $\mathrm{CAO}^{a,{ }^{*}}$, \\ Jingxin $\mathrm{LI}^{a}$, Jie $\mathrm{CHEN}^{a}$, Lu ZHANG ${ }^{b}$, Zheng $\mathrm{QI}^{b}$ \\ ${ }^{a}$ Science and Technology on Thermostructural Composites Materials Laboratory, \\ Northwestern Polytechnical University, Xi' an 710072, China \\ ${ }^{b}$ Science and Technology on Space Physics Laboratory, Beijing 100076, China
}

Received: May 3, 2021; Revised: July 26, 2021; Accepted: August 9, 2021

(C) The Author(s) 2021.

\begin{abstract}
In this work, pitch-based carbon fibers were utilized to reinforce silicon carbide ( $\mathrm{SiC}$ ) composites via reaction melting infiltration (RMI) method by controlling the reaction temperature and resin carbon content. Thermal conductivities and bending strengths of composites obtained under different preparation conditions were characterized by various analytical methods. Results showed the formation of $\mathrm{SiC}$ whiskers $\left(\mathrm{SiC}_{\mathrm{w}}\right)$ during $\mathrm{RMI}$ process according to vapor-solid (VS) mechanism. $\mathrm{SiC}_{\mathrm{w}}$ played an important role in toughening the $\mathrm{C}_{\mathrm{p} f} / \mathrm{SiC}$ composites due to crack bridging, crack deflection, and $\mathrm{SiC}_{\mathrm{w}}$ pull-out. Increase in reaction temperature during RMI process led to an initial increase in thermal conductivity along in-plane and thickness directions of composites, followed by a decline. At reaction temperature of $1600{ }^{\circ} \mathrm{C}$, thermal conductivities along the in-plane and thickness directions were estimated to be 203.00 and $39.59 \mathrm{~W} /(\mathrm{m} \cdot \mathrm{K})$, respectively. Under these conditions, bending strength was recorded as $186.15 \pm 3.95 \mathrm{MPa}$. Increase in resin carbon content before RMI process led to the generation of more $\mathrm{SiC}$ matrix. Thermal conductivities along in-plane and thickness directions remained stable with desirable values of 175.79 and $38.86 \mathrm{~W} /(\mathrm{m} \cdot \mathrm{K})$, respectively. By comparison, optimal bending strength improved to $244.62 \pm 3.07 \mathrm{MPa}$. In sum, these findings look promising for future application of pitch-based carbon fibers for reinforcement of $\mathrm{SiC}$ ceramic composites.
\end{abstract}

Keywords: pitch-based carbon fiber; continuous carbon fiber reinforced silicon carbide matrix composites $(\mathrm{C} / \mathrm{SiC})$; thermal conductivity; bending strength

\section{Introduction}

Continuous carbon fiber reinforced silicon carbide matrix composites $(\mathrm{C} / \mathrm{SiC})$ are promising thermal structural

\footnotetext{
* Corresponding authors.

E-mail: Y. Liu, yongshengliu@nwpu.edn.cn; Y. Cao, caoyejie@nwpu.edu.cn
}

materials with low density, high specific strength, superior specific modulus, elevated temperature resistance, good wear resistance, and relevant chemical resistance [1-3], which make them useful for applications in aerospacerelated fields. As a result, comprehensive research investigations have been focused on the preparation technologies, such as chemical vapor infiltration (CVI), reaction melting infiltration (RMI), and polymer infiltration 
pyrolysis (PIP), as well as the mechanical properties of obtained $\mathrm{C} / \mathrm{SiC}$ composites to satisfy the increasingly stringent demands for new types of aerospace vehicles and advanced engines [4,5].

However, the poor heat conduction of $\mathrm{C} / \mathrm{SiC}$ composites along the in-plane and thickness directions has limited their wider applications. In recent years, numerous research investigations have been devoted to improving the thermal conductivity of $\mathrm{C} / \mathrm{SiC}$ composites [6-11]. One of the most widely used approaches is the incorporation of materials with high thermal conductivity into ceramic materials. For instance, Chen et al. [9] utilized PIP method to produce $\mathrm{C} / \mathrm{SiC}$ composites with vertically aligned carbon nanotubes (CNTs) on carbon fiber preform. The thermal conductivity in throughthickness direction of the resulting materials reached $16.8 \mathrm{~W} /(\mathrm{m} \cdot \mathrm{K})$. Yang et al. [10] successfully improved the thermal conductivity of $\mathrm{C} / \mathrm{SiCN}$ composites to 5.6 $\mathrm{W} /(\mathrm{m} \cdot \mathrm{K})$ by embedding CNTs into inter-bundle spaces of two adjacent carbon fiber sheets by the vacuum infiltration method. Feng et al. [11] introduced bucky-papers (CNT film) into SiC fiber preform to prepare $\mathrm{SiC}_{\mathrm{f}}-\mathrm{CNTs} / \mathrm{SiC}$ composites with layered matrix structures. The thermal conductivity of the as-obtained material was found to be $23.9 \mathrm{~W} /(\mathrm{m} \cdot \mathrm{K})$, which was 2.9-fold higher than that of the traditional $\mathrm{SiC} / \mathrm{SiC}$ composites. Besides, we previously developed a novel approach based on the introduction of heat transfer channels into $\mathrm{C} / \mathrm{SiC}$ composites to yield better thermal conductivities [8,12]. Cao et al. [8] employed laser assisted-chemical vapor infiltration (LA-CVI) method to fabricate $\mathrm{CNT} / \mathrm{SiC}$ micro-pillars in $\mathrm{C} / \mathrm{SiC}$ composites as heat transfer channels to yield improved thermal conductivity of $20.69 \mathrm{~W} /(\mathrm{m} \cdot \mathrm{K})$. Zhang et al. [12] inserted pitch-based carbon fiber along the thickness direction of $\mathrm{C} / \mathrm{SiC}$ composites to construct heat conductive micro-pipelines with the highest thermal conductivity of $32.70 \mathrm{~W} /(\mathrm{m} \cdot \mathrm{K})$. However, the above studies are based on the use of CNTs or other materials to modify the composites or construction of heat conduction channels inside the composites, which still lack control and stability due to the uncontrollable behaviors of CNTs or other nanomaterials at the nanoscale, as well as the difficulties encountered with various preparation techniques $[8,12]$.

Polyacrylonitrile (PAN)-based carbon fibers, such as $\mathrm{T} 300$ and T700, are preferred fiber reinforcement materials used in $\mathrm{C} / \mathrm{SiC}$ composites for aerospace applications due to their excellent mechanical properties
$[13,14]$. However, the thermal conductivity of PAN-based carbon fibers along the radial direction is only about $4.9 \mathrm{~W} /(\mathrm{m} \cdot \mathrm{K})$ [15], resulting in limited improvement of thermal conductivity of $\mathrm{C} / \mathrm{SiC}$ composites. Pitch-based carbon fibers derived from mesophase pitch have superior modulus and high thermal conductivity that may reach hundreds of folds that of PAN carbon fibers. Hence, pitch-based carbon fibers have great potential in aerospace, medical treatment, construction, sports equipment, and many other application fields [16-18]. Recently, pitch-based carbon fibers have mainly been used in carbon matrix composites, while few research studies have been reported on the use of pitch-based carbon fibers to reinforce ceramic matrix composites. For example, Odeshi et al. [16] compared C/C-SiC composites reinforced by PAN-based carbon fiber and pitch-based carbon fiber. They found that $\mathrm{C} / \mathrm{C}-\mathrm{SiC}$ composites prepared by pitch-based carbon fiber possessed higher flexural strength $(152 \mathrm{MPa})$ than PAN-based carbon fiber (133 MPa), which can be attributed to the longer load transfer length of the pitch-based fiber compared to PAN-based fiber. Servadei et al. [19] fabricated $\mathrm{C}_{\mathrm{f}} / \mathrm{ZrB}_{2}-\mathrm{SiC}$ composites reinforced by ultra-high modulus pitch-based carbon fiber via PIP process. The bending strengths of carbon preform constituted by $0^{\circ}$, $0^{\circ} / 90^{\circ}$, and $2 \mathrm{D}$ were found to be 500,370 , and 190 $\mathrm{MPa}$, respectively. Mainzer et al. [20] used pitch-based fibers to produce $\mathrm{C} / \mathrm{SiCN}$ composites via PIP method with a tensile strength of $288 \mathrm{MPa}$. Therefore, pitch-based carbon fiber reinforced ceramic matrix composites are promising but their potential in the engineering field is still untapped.

The RMI process is effective for the rapid fabrication of ceramic matrix composites with high density [21]. The phase composition and microstructure caused by factors such as reaction rate, melt viscosity, behavior of silicon during phase transition, and wetting of reinforcement, are critical for successful composites. Li et al. [22] studied the effects of different diamond concentrations on thermal conductivities of diamond- $\mathrm{C} / \mathrm{SiC}$ produced by RMI method. They found that higher diamond concentrations led to improved density $\left(2.18 \mathrm{~g} / \mathrm{cm}^{3}\right)$, bending strength (309.01 MPa), and thermophysical properties (thermal conductivity: $14.68 \mathrm{~W} /(\mathrm{m} \cdot \mathrm{K})$, thermal expansion coefficient: $2.69 \times 10^{-6} \mathrm{~K}^{-1}$ ) of the resulting composites. Zhong et al. [23] fabricated novel hierarchically porous carbon structures in fiber preform with a median pore size of $1.8 \mu \mathrm{m}$. The as-formed 
$\mathrm{C} / \mathrm{SiC}$ composites exhibited tensile strength of $159 \pm 5$ $\mathrm{MPa}$, a value of $46 \%$ higher than that of normal $\mathrm{C} / \mathrm{SiC}$ composites.

In this work, pitch-based carbon fiber reinforced $\mathrm{SiC}$ composites were obtained by CVI combined with RMI process. The effects of reaction temperature and resin carbon content during RMI process on the microstructures and phase compositions of the composites were investigated. The bending strengths and thermal conductivities of $\mathrm{C}_{\mathrm{p} f} / \mathrm{SiC}$ composites were thoroughly studied. $\mathrm{SiC}_{\mathrm{w}}$ samples were also constructed, and both growth and action mechanisms were investigated. The results indicated that $\mathrm{C}_{\mathrm{pf}} / \mathrm{SiC}$ composites possessed good bending strength and excellent thermal conductivity.

\section{Experimental}

\section{1 Materials}

Mesophase pitch-based carbon fibers TC-HC-500 (Shaanxi Tiance New Materials Technology Co., Ltd., China) were used as reinforcement for $\mathrm{C} / \mathrm{SiC}$ composites. Phenolic resin (Henan Hengtong Chemical Co., Ltd., China) was utilized as a carbon source for the reaction with molten $\mathrm{Si}$ (thermosetting resin).

\section{2 Preparation of $\mathrm{C}_{\mathrm{pf}} / \mathrm{SiC}$ composites}

Pitch-based carbon fiber was abbreviated as PB-fiber. Basic property of $\mathrm{T} 300$ and $\mathrm{PB}$-fibers are listed in Table 1. SiC composites reinforced by pitch-based carbon fibers in this work were named as $\mathrm{C}_{\mathrm{pf}} / \mathrm{SiC}$. As depicted in Fig. 1, the PB-fibers were woven into unidirectional fiber sheets and stacked by needle-punching along the $0^{\circ} / 90^{\circ}$ direction to fabricate fiber preform.
The fiber volume content of the composites was $43 \%$.

The combined CVI-RMI process mainly consisted of two steps. The first step was the preparation of porous $\mathrm{C}_{\mathrm{p} f} / \mathrm{SiC}$ composites by CVI. To this end, PyC interphase (150 nm in thickness) was deposited on the preform, and then treated at $1800{ }^{\circ} \mathrm{C}$ for $2 \mathrm{~h}$ under vacuum to eliminate residual thermal stress. Thereafter, $\mathrm{SiC}$ matrix was infiltrated into the porous preform via CVI for $280 \mathrm{~h}$ at $1100{ }^{\circ} \mathrm{C}$. During the CVI process, methyltrichlorosilane (MTS, $\mathrm{CH}_{3} \mathrm{SiCl}_{3}$ ) was used as a precursor, and the process was carried out by bubbling hydrogen. Argon was employed as the diluent gas to slow down the reaction rate, and the pressure of the whole system was controlled at $5 \mathrm{kPa}$. After 3-4 CVI cycles in the furnace, the density of $\mathrm{C}_{\mathrm{pf}} / \mathrm{SiC}$ composites reached $1.6 \mathrm{~g} / \mathrm{cm}^{3}$.

The second step consisted of the densification process by RMI. To this end, phenolic resin powder and absolute ethanol were mixed at the mass ratio of 1:3 to obtain a phenolic resin solution. After infiltration by resin solution in vacuum pot for $30 \mathrm{~min}, \mathrm{C}_{\mathrm{pf}} / \mathrm{SiC}$ composites with resin were pyrolyzed under argon (purity $\geqslant$ $99.999 \%$ ) at $950{ }^{\circ} \mathrm{C}$ for $2 \mathrm{~h}$ to transform the polymer carbon into amorphous carbon, representing the end of one cycle of impregnation. After pyrolysis, the change in mass of the samples was recorded, and samples were embedded with superfluous Si powders followed by wrapping with graphite papers. Next, the samples were placed in a Si-infiltration furnace for $30 \mathrm{~min}$ under vacuum to yield $\mathrm{C}_{\mathrm{pf}} / \mathrm{SiC}$ composites.

Siliconization samples prepared at 1500, 1600, 1700, and $1800{ }^{\circ} \mathrm{C}$ were denoted as T15\#, T16\#, T17\#, and T18\#, respectively. Porous samples were infiltrated with resin and pyrolyzed for $2,4,6$, and 8 times to yield composites $2 \mathrm{CH}, 4 \mathrm{C} \#, 6 \mathrm{CH}$, and $8 \mathrm{CH}$, respectively.

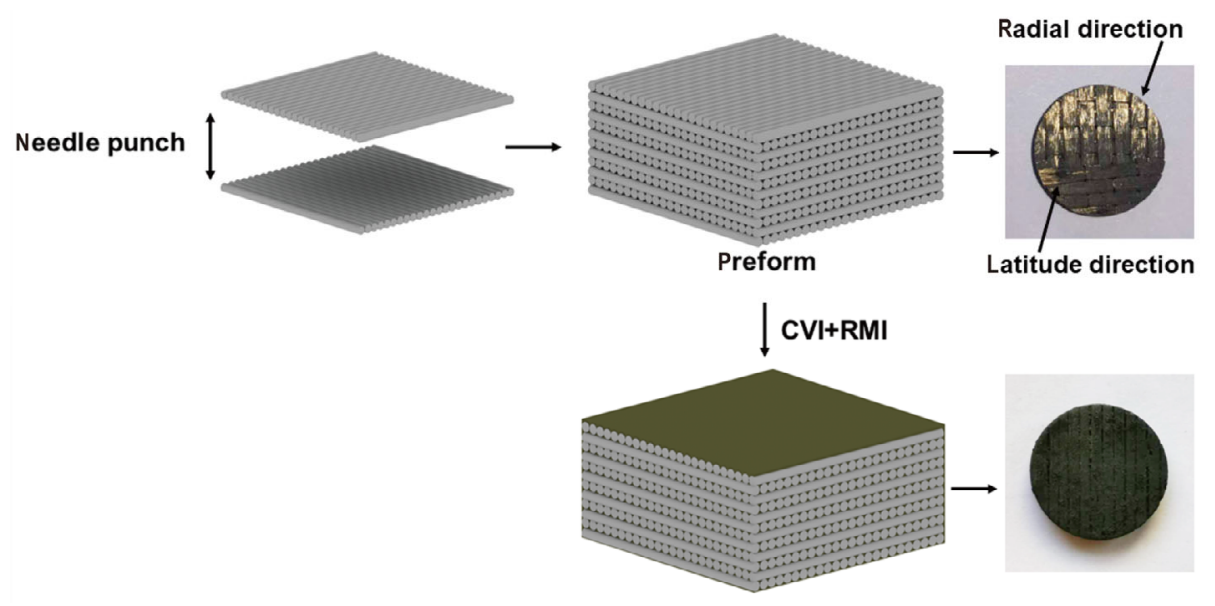

Fig. 1 Schematic diagram showing the pitch-based carbon fiber sheet, fiber preform, and composites. 
Table 1 Properties of T300 and PB-fibers [15]

\begin{tabular}{ccccc}
\hline $\begin{array}{c}\text { Carbon } \\
\text { fiber }\end{array}$ & $\begin{array}{c}\text { Thermal } \\
\text { conductivity } \\
(\mathrm{W} /(\mathrm{m} \cdot \mathrm{K}))\end{array}$ & $\begin{array}{c}\text { Strength } \\
(\mathrm{MPa})\end{array}$ & $\begin{array}{c}\text { Modulus } \\
(\mathrm{GPa})\end{array}$ & $\begin{array}{c}\text { Linear density } \\
\left(\mathrm{g} / \mathrm{cm}^{3}\right)\end{array}$ \\
\hline T300 & 4.9 & 3530 & 230 & 0.06 \\
PB-fibers & 480 & 2078 & 806 & 0.46 \\
\hline
\end{tabular}

\section{3 Characterization}

The density and open porosity of the composites were measured by the Archimedes method, and the results are gathered in Table 2. The crystal phases of the samples were identified by X-ray diffraction (XRD; Rigaku D/max-2400, Japan). Raman spectrum was conducted by a Raman spectroscopy (confocal Raman microscope, Renishaw, Beijing, China). Three-point bending tests were carried out by an electro-mechanical universal testing system (Instron 5567, UK) at room temperature and a loading rate of $0.5 \mathrm{~mm} / \mathrm{min}$. To this end, the prepared composites were processed into 40 $\mathrm{mm} \times 5 \mathrm{~mm} \times 3 \mathrm{~mm}$ specimens for use in each test. The microstructures of the composites were characterized by the scanning electron microscope (SEM; FEI, Helios G4 CX, USA) equipped with the energy dispersive spectrometer (EDS) and the back-scattered electron (BSE) detector. The thermodynamic properties were calculated by the FactSage software (Thermfact/CRCT, Canada and GTT-Technologies, Germany). The thermal diffusivity $(\alpha)$ and heat capacity $\left(C_{p}\right)$ of each sample were measured by the laser flash method (LFA 427, NETZSCH, Germany) at a heating rate of $2{ }^{\circ} \mathrm{C} / \mathrm{min}$. The thermal conductivity $(\lambda)$ of each composite was calculated according to the equation: $\lambda=\alpha \times C_{p} \times \rho$, where $\rho$ is the specimen density and $C_{p}$ is the specific heat capacity. The sample sizes in through-thickness and in-plane directions were $\Phi 12.7 \mathrm{~mm} \times 3 \mathrm{~mm}$ and $10 \mathrm{~mm} \times 5 \mathrm{~mm} \times 3 \mathrm{~mm}$, respectively.

Table 2 Properties of $\mathrm{C}_{\mathrm{p} f} / \mathrm{SiC}$ composites at different siliconization temperatures

\begin{tabular}{ccrrc}
\hline \multirow{2}{*}{ Sample } & $\begin{array}{c}\text { Density } \\
\left(\mathrm{g} / \mathrm{cm}^{3}\right)\end{array}$ & $\begin{array}{c}\text { Porosity } \\
(\%)\end{array}$ & \multicolumn{2}{c}{ Thermal conductivity $(\mathrm{W} /(\mathrm{m} \cdot \mathrm{K}))$} \\
\cline { 4 - 5 } & & & In-plane & Through-thickness \\
\hline RMI C/SiC & 2.18 & 8.67 & 15.62 & 7.55 \\
T15\# & 2.31 & 11.64 & 174.03 & 35.44 \\
T16\# & 2.35 & 9.96 & 203.00 & 39.59 \\
T17\# & 2.22 & 13.26 & 151.96 & 28.16 \\
T18\# & 2.17 & 15.10 & 145.31 & 16.98 \\
\hline
\end{tabular}

\section{Results and discussion}

\section{1 Microstructures and morphologies of pitch-based carbon fibers}

The crystal structures of the two types of carbon fibers were analyzed by XRD, and the results are shown in Fig. 2(a). The interplanar spacing $\left(d_{002}\right)$ and half-peak width of (002) peak can reveal the graphitization degree of carbon fibers [24]. Smaller $d_{002}$ values and narrower (002) peak indicated more integrated crystallinity and higher degree of graphitization [25]. Additionally, the half-peak width of (002) peak in the equatorial scanning patterns of the fibers (Fig. 2) was used to calculate the graphite microcrystalline stacking thickness $\left(L_{\mathrm{C}}\right)$. Smaller half-peak widths demonstrated larger stack thicknesses and more stacked graphite layers. The $d_{002}$ values were obtained by the Bragg equation (Eq. (1)) [26], where $\lambda$ is the wavelength of the X-ray $\left(\mathrm{Cu} \mathrm{K} \alpha_{1}, 1.54060 \mathrm{~nm}\right)$ and $\theta$ represents the half-peak width (in radian). The $L_{\mathrm{C}}$ values were calculated by the Scherrer formula (Eq. (2)) [27], where $K$ is the Scherrer factor (also known as the shape factor or $K=0.92$ ), and $\beta$ is the full width at half maximum of the diffraction peak. The XRD structural parameters of the two types of fibers are listed in Table 3.

$$
\begin{gathered}
d_{002}=\frac{\lambda}{2 \sin \theta} \\
L_{\mathrm{C}}=\frac{K \lambda}{\beta \cos \theta}
\end{gathered}
$$

As depicted in Fig. 2(a) and Table 3, the two types of carbon fibers showed a radiating peak at about $2 \theta=25^{\circ}$ with significantly different features. Compared to T300, PB-fibers displayed a strong and sharp (002) peak, as well as smaller interplanar spacing and thicker stacked sizes. These features indicated larger microcrystal dimension, higher degree of graphitization, and more complete stacking of graphite microcrystals.

The as-obtained composites were further analyzed by the Raman spectroscopy $[25,28]$. As shown in Fig. 2(b), the two types of carbon fibers exhibited typical Raman bands identified as D peak and G peak. The intensity of $G$ peak was used to characterize the integrity of $\mathrm{sp}^{2}$ hybridized structure in graphite, while

Table 3 XRD structural parameters of T300 and PB-fibers

\begin{tabular}{ccccc}
\hline Fiber & $\begin{array}{c}\text { Diffraction } \\
\text { angle }\left(^{\circ}\right)\end{array}$ & $\begin{array}{c}\text { Interplanar } \\
\text { spacing } d_{002}(\mathrm{~nm})\end{array}$ & FWHM & $\begin{array}{c}\text { Stack thickness } \\
L_{\mathrm{C}}(\mathrm{nm})\end{array}$ \\
\hline T300 & 26.23 & 0.361 & 6.63 & 1.22 \\
PB-fibers & 26.56 & 0.339 & 0.77 & 14.62 \\
\hline
\end{tabular}



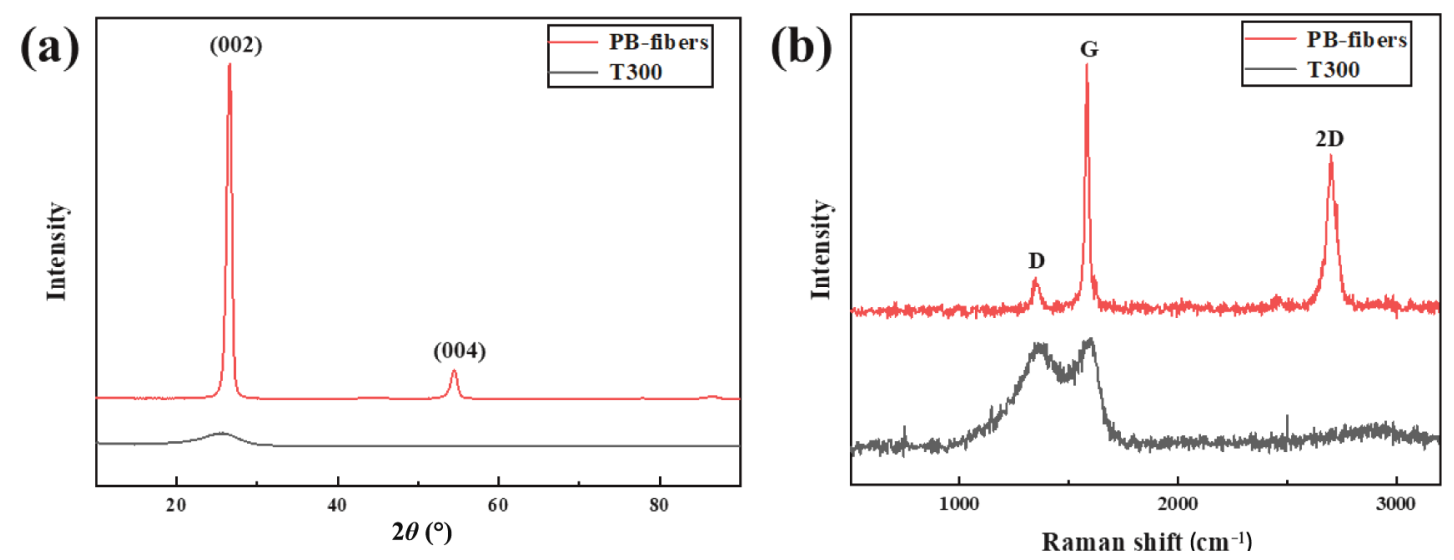

Fig. 2 XRD patterns and Raman spectra of T300 and PB-fibers.

D peak was employed to study the degree of orientation and structural defects in graphite. The 2D peak $\left(2700 \mathrm{~cm}^{-1}\right)$ in Raman spectrum was also utilized to identify the monolayer and multilayer of graphene [29], which verified the layered graphite structure of PB-fibers. The intensity ratio $(R)$ of $\mathrm{D}$ to $\mathrm{G}$ peak was used to estimate the degree of graphitization, where a lower $R$-value represents a higher degree of graphitization. In Fig. 2(b), the larger strength of D peak in T300 yielded broad and overlapped D peak and G peak, suggesting incomplete graphite structures and disordered lamellars of T300. Tuinstra and Koenig [30] observed a linear relationship between $R$ and reciprocal value of grain size in crystal plane $\left(L_{\mathrm{a}}\right)$ according to the empirical formula shown by Eq. (3). The Raman structural parameters of the two fibers are compiled in Table 4.

$$
L_{\mathrm{a}}=\frac{4.4}{R}
$$

The cross-sectional SEM images of the two types of fibers are presented in Fig. 3. Both fibers displayed significant differences in the order of graphite structures. The structures of carbon fibers were made of disorderly lamellar graphite structures. Bennet et al. [31] proposed a skin-core model to describe the microstructure of carbon fibers. They found high modulus carbon fiber to possess layers of graphite microcrystals arranged orderly along the fiber axis in the cortex. The cores showed a slightly disordered shape of folds with intricate pore structures between the layers of graphite. The skin-core model could accurately describe the microstructures of PB-fibers. Compared to PB-fibers, the graphite microcrystals of T300 were tightly stacked but in a disordered manner. These data were consistent with the XRD and Raman analyses.

\section{2 Growth mechanism of SiC whiskers}

As shown in Fig. 4, large amounts of SiC whiskers ( $\mathrm{SiC}_{\mathrm{w}}$, diameter: $\sim 0.8 \mu \mathrm{m}$ ) were formed during $\mathrm{RMI}$ process. Note that $\mathrm{SiC}_{\mathrm{w}}$ was characterized by a single crystal with a high orientation (diameter from nanometer to micrometer). Besides, $\mathrm{SiC}_{\mathrm{w}}$ possessed few chemical impurities, no grain boundaries, few crystal defects, and uniform crystalline phase composition. These features

Table 4 Raman structural parameters of T300 and PB-fibers

\begin{tabular}{ccc}
\hline Fiber & $R=I_{\mathrm{D}} / I_{\mathrm{G}}$ & $L_{\mathrm{a}}(\mathrm{nm})$ \\
\hline T300 & 2.96 & 1.49 \\
PB-fibers & 0.14 & 31.43 \\
\hline
\end{tabular}

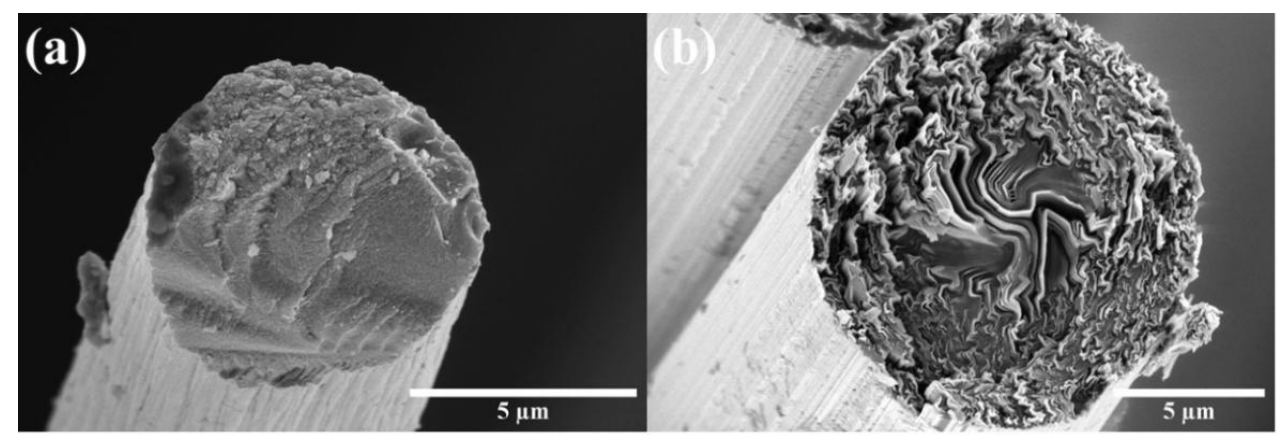

Fig. 3 Microstructures of cross-sections: (a) T300 and (b) PB-fibers. 
provided $\mathrm{SiC}_{\mathrm{w}}$ with good specific strength, high specific elastic modulus, and high thermal conductivity. In the following sections, $\mathrm{C}_{\mathrm{p} f} / \mathrm{SiC}$ composites are produced at different siliconization temperatures; therefore, the different growth mechanisms of $\mathrm{SiC}_{\mathrm{w}}$ at various siliconization temperatures should be discussed first.

According to the studies [32-34], $\mathrm{SiC}_{\mathrm{w}}$ can be synthesized without the assistance of a catalyst. In other words, $\mathrm{C}$ and $\mathrm{Si}$ can directly react to form $\mathrm{SiC}_{\mathrm{w}}$. Wei et al. [34] studied the growth mechanism of SiC nanowires prepared by ball-milled activated carbon and vaporized silicon at $1600{ }^{\circ} \mathrm{C}$ without a catalyst. Their results identified vapor-solid (VS) interaction as the dominant mechanism. Li et al. [33] synthesized $\mathrm{SiC}_{\mathrm{w}}$ using reactive graphite as a template and found that graphite with a higher density of defects could accelerate the formation of $\mathrm{SiC}_{\mathrm{w}}$. The studies of Dai et al. [32] and Chen et al. [35] indicated that the formation of $\mathrm{SiC}_{\mathrm{w}}$ was achieved by three main stages, which included the generation of intermediate products, the formation of $\mathrm{SiC}$ nuclei, and the growth of $\mathrm{SiC}_{\mathrm{w}}$. The related reactions (several intermediate reactions included) are shown as Reactions (4)-(10). To further understand the growth mechanism of SiC whiskers in this work, the Gibbs free energy of the reaction at various temperatures $\left(1500-1800{ }^{\circ} \mathrm{C}\right)$ was calculated by FactSage software. The reaction can happen spontaneously when the Gibbs free energy is less than 0 . The standard Gibbs free energy of each reaction is shown in Fig. 5.

$$
\begin{gathered}
\mathrm{C}(\mathrm{g})+\mathrm{SiO}_{2}(\mathrm{~s})=\mathrm{SiO}(\mathrm{g})+\mathrm{CO}(\mathrm{g}) \\
\mathrm{CO}(\mathrm{g})+\mathrm{SiO}_{2}(\mathrm{~s})=\mathrm{SiO}(\mathrm{g})+\mathrm{CO}_{2}(\mathrm{~g}) \\
\mathrm{Si}(\mathrm{g})+\mathrm{SiO}_{2}(\mathrm{~s})=2 \mathrm{SiO}(\mathrm{g}) \\
\mathrm{SiO}(\mathrm{g})+2 \mathrm{C}(\mathrm{s})=\mathrm{SiC}(\mathrm{s})+\mathrm{CO}(\mathrm{g}) \\
\mathrm{Si}(\mathrm{g})+\mathrm{C}(\mathrm{s})=\mathrm{SiC}(\mathrm{s}) \\
3 \mathrm{SiO}(\mathrm{g})+\mathrm{CO}(\mathrm{g})=\mathrm{SiC}(\mathrm{s})+2 \mathrm{SiO}_{2}(\mathrm{~g}) \\
\mathrm{SiO}(\mathrm{g})+3 \mathrm{CO}(\mathrm{g})=\mathrm{SiC}(\mathrm{s})+2 \mathrm{CO}_{2}(\mathrm{~g})
\end{gathered}
$$

First, the intermediate products $\mathrm{SiO}$ and $\mathrm{CO}$ were produced via Reactions (4)-(6). As depicted in Fig. 5(a), Reaction (5) had positive Gibbs free energy at 1500-1800 ${ }^{\circ} \mathrm{C}$, and Reaction (6) had negative Gibbs free energy, which demonstrated that generation of $\mathrm{SiO}$ and $\mathrm{CO}$ was mainly due to Reactions (4) and (6) (greater than around $1650{ }^{\circ} \mathrm{C}$ ). Second, the Gibbs free energy in Fig. 5(b) had negative value, which illustrated that the formation of $\mathrm{SiC}$ nuclei could happen completely spontaneously and mainly contributed by Reaction (7) (lower Gibbs free energy). Finally, as shown in Fig. 5(c), the growth of $\mathrm{SiC}_{\mathrm{w}}$ was basically dominated by Reactions ( 8 ) and (9). When the temperature exceeded around $1740{ }^{\circ} \mathrm{C}$, Reaction (8) was the only reaction for $\mathrm{SiC}_{\mathrm{w}}$ growth.

Based on the above analysis, the growth mechanism of $\mathrm{SiC}_{\mathrm{w}}$ in the present work can be concluded as follows: VS mechanism governed the whole process. At 1500 and $1600{ }^{\circ} \mathrm{C}$, the dominant reactions were Reactions (6)-(9). At $1700{ }^{\circ} \mathrm{C}$, the dominant reactions were Reactions (4) and (6)-(9). At $1800{ }^{\circ} \mathrm{C}$, the

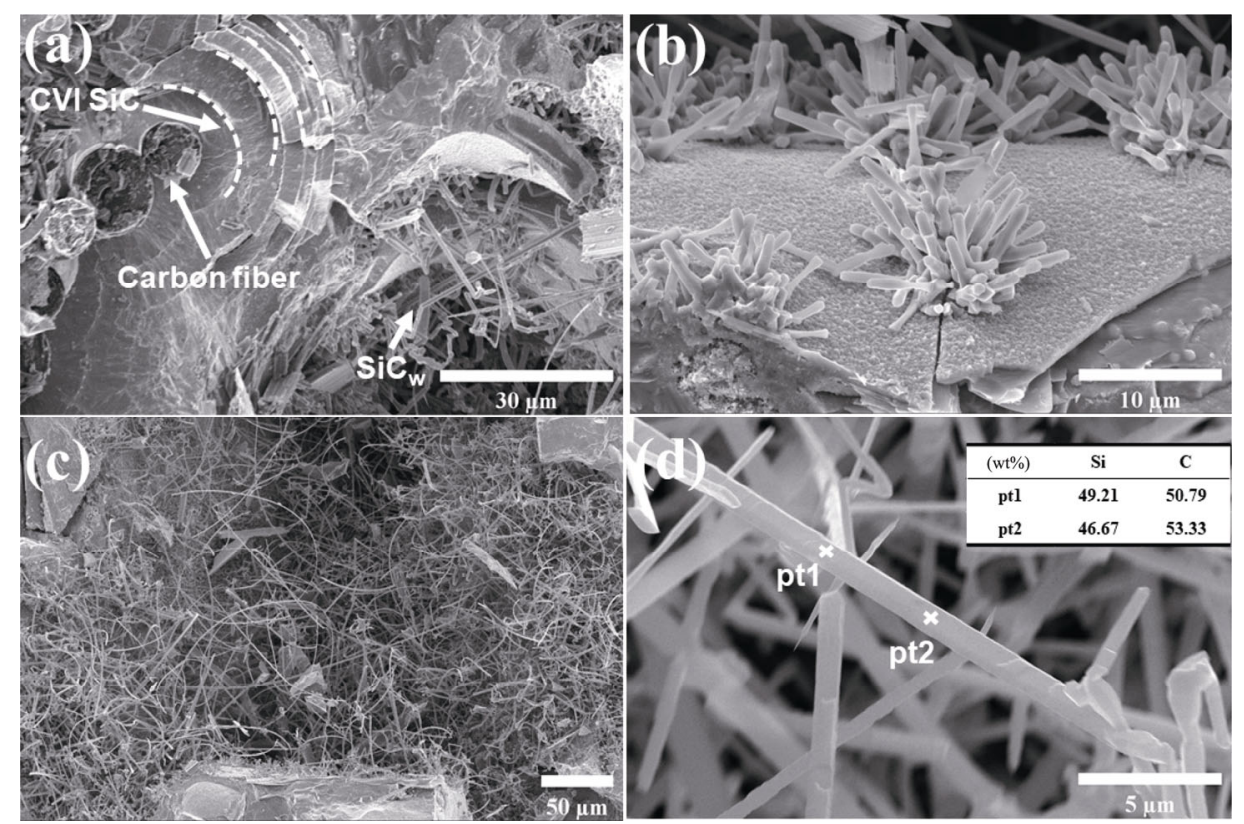

Fig. 4 Microstructures and EDS analyses of $\mathrm{SiC}_{\mathrm{w}}$. 

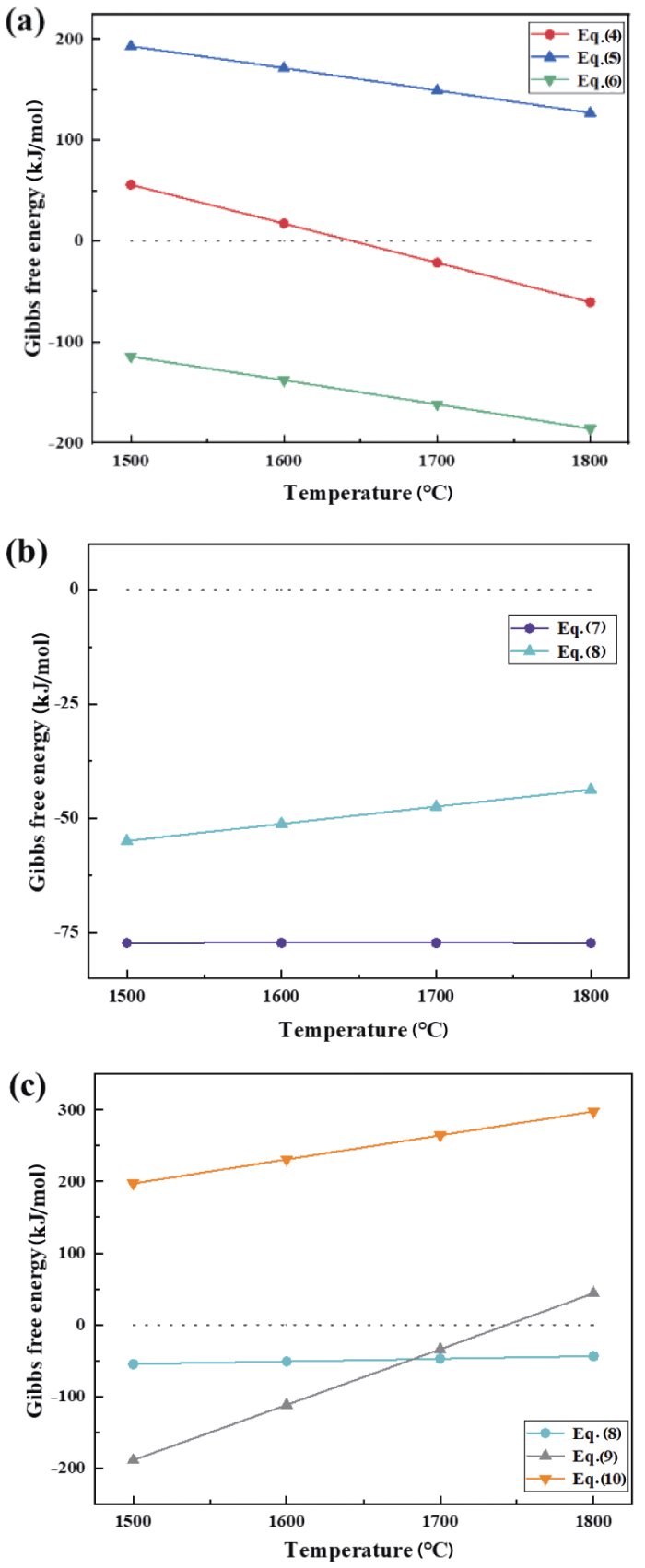

Fig. 5 Gibbs free energy change of Reactions (4)-(10) calculated by FactSage software: (a) formation of intermediate products, (b) formation of $\mathrm{SiC}$ nuclei, and (c) growth of $\mathrm{SiC}_{\mathrm{w}}$.

dominant reactions were Reactions (4) and (6)-(8). Si, carbon, and porous $\mathrm{C}_{\mathrm{pf}} / \mathrm{SiC}$ composites provided a good environment for $\mathrm{SiC}_{\mathrm{w}}$ growth. In Fig. 4(a), $\mathrm{SiC}_{\mathrm{w}}$ grew on the outside of the layered CVI SiC matrix, suggesting that $\mathrm{SiC}_{\mathrm{w}}$ was formed during RMI instead of CVI process. The O-element involved in the reaction processes originated from $\mathrm{SiO}_{2}$ in commercial $\mathrm{Si}$ powder. The schematic diagram of the growth of
$\mathrm{SiC}_{\mathrm{w}}$ is depicted in Fig. 6. First, $\mathrm{SiO}$ and $\mathrm{CO}$ were generated by Reactions (4)-(6). Then, the superfluous $\mathrm{Si}$ vapor and $\mathrm{SiO}$ vapor were adsorbed on the residual carbon (activated carbon atoms) surface during RMI process and reacted to form $\mathrm{SiC}$ nucleus. Later, $\mathrm{SiC}_{\mathrm{w}}$ grew along (111) direction [32,34,35] of $\mathrm{SiC}$ nucleus to form long and randomly oriented $\mathrm{SiC}_{\mathrm{w}}$ following Reactions (8) and (9), according to the literature.

\section{3 Thermal conductivity of $\mathrm{C}_{\mathrm{pf}} / \mathrm{SiC}$ composites}

\subsubsection{Effects of different siliconization temperatures}

The melt infiltration process can use almost any reinforced geometry to yield high-density and low-porosity matrices. Different reaction temperatures (beyond the melting point of silicon, $1415{ }^{\circ} \mathrm{C}$ ) of RMI can lead to various phase compositions and microstructures, thereby affecting the properties of $\mathrm{C}_{\mathrm{p} f} / \mathrm{SiC}$ composites. Table 2 summarizes the properties of $\mathrm{C}_{\mathrm{p} f} / \mathrm{SiC}$ composites prepared at different siliconization temperatures. The thermal conductivities in this work were measured at $35{ }^{\circ} \mathrm{C}$. Note that the densities were repeatedly measured, and the obtained thermal conductivities were averaged to yield the values shown in Table 2. The data of traditional $\mathrm{RMI} \mathrm{C} / \mathrm{SiC}$ were collected from our database and were compared with the composites in this work. Apparently, composites in this work possessed excellent thermal conductivity. As can be seen, the densities of composites increased first with the reaction temperature and then decreased, and maximum density was recorded at $1600{ }^{\circ} \mathrm{C}$. As shown in Fig. 7, the microstructures of the composites were consistent with the changing trend of density. The reaction between $\mathrm{Si}$ and $\mathrm{C}$ was theoretically more efficient at high temperatures. However, the exothermic reaction between $\mathrm{Si}$ and $\mathrm{C}$ resulted in excess local temperature and vaporization of large amounts of $\mathrm{Si}$ $[36,37]$. At reaction temperatures of 1500 and $1600{ }^{\circ} \mathrm{C}$ (Fig. 8), the reactants $\mathrm{Si}$ and $\mathrm{C}$ displayed weaker peaks, while the product $\mathrm{SiC}$ illustrated stronger peaks. At temperatures of 1600 and $1700{ }^{\circ} \mathrm{C}$, the $\mathrm{C}$ peaks became extremely strong but the Si peaks weakened or even vanished. Hence, large amounts of Si vaporized while the graphitized resin carbon remained in the composites. The incomplete reaction between $\mathrm{Si}$ and $\mathrm{C}$ resulted in porous microstructures of T17\# and T18\#, while larger-sized pores remained. On the other hand, the reaction rate of $\mathrm{Si}$ and $\mathrm{C}$ was too fast and was much higher than the flow rate of liquid $\mathrm{Si}$ at high 

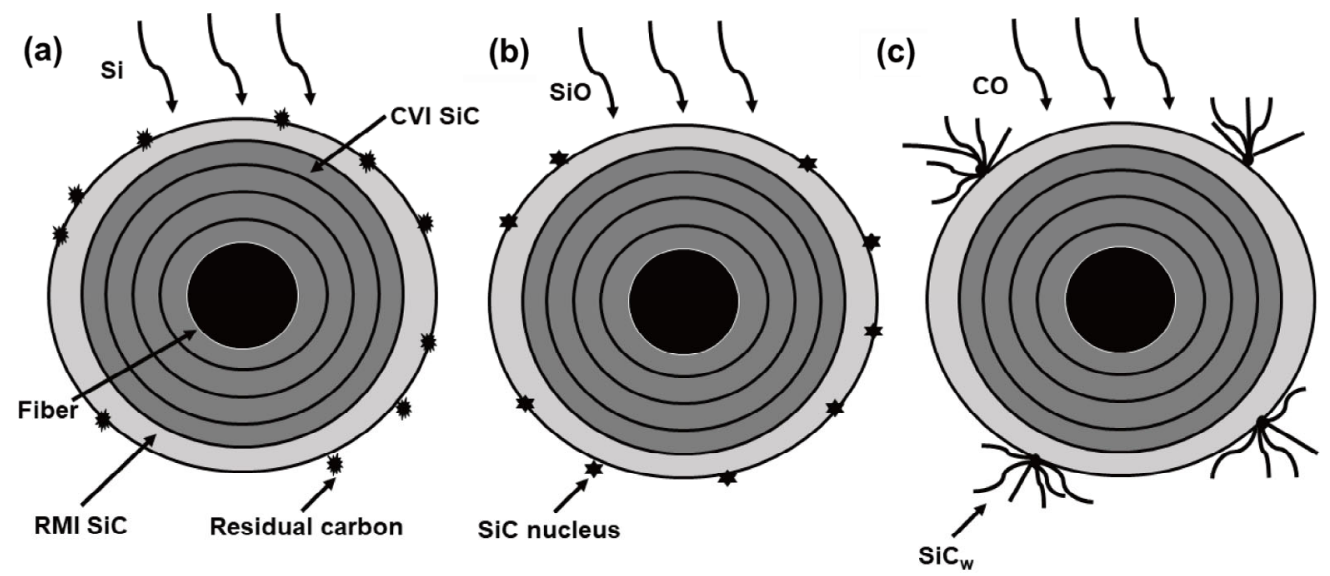

Fig. 6 Schematic diagram showing the formation of $\mathrm{SiC}_{\mathrm{w}}$.
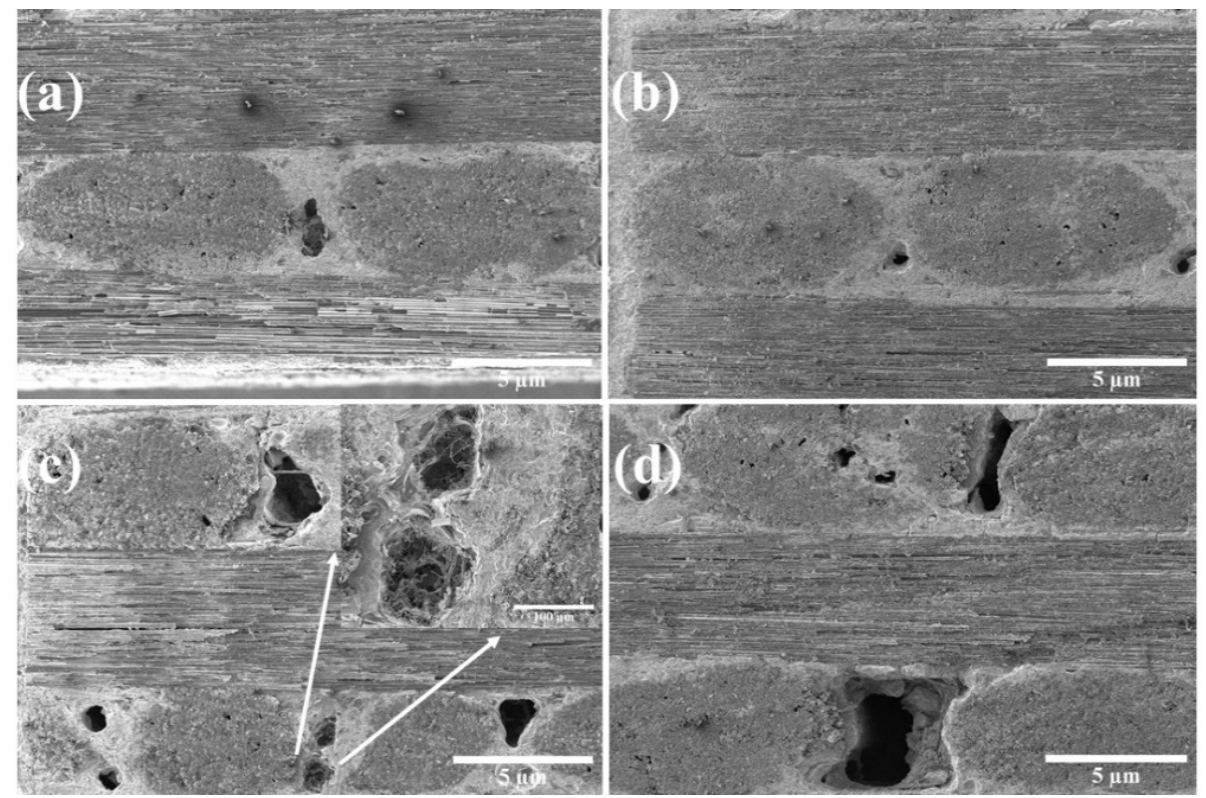

Fig. 7 Microstructures of $\mathrm{C}_{\mathrm{pf}} / \mathrm{SiC}$ composites prepared at different siliconization temperatures: (a) $1500{ }^{\circ} \mathrm{C}$, (b) $1600{ }^{\circ} \mathrm{C}$, (c) $1700{ }^{\circ} \mathrm{C}$, and (d) $1800{ }^{\circ} \mathrm{C}$.

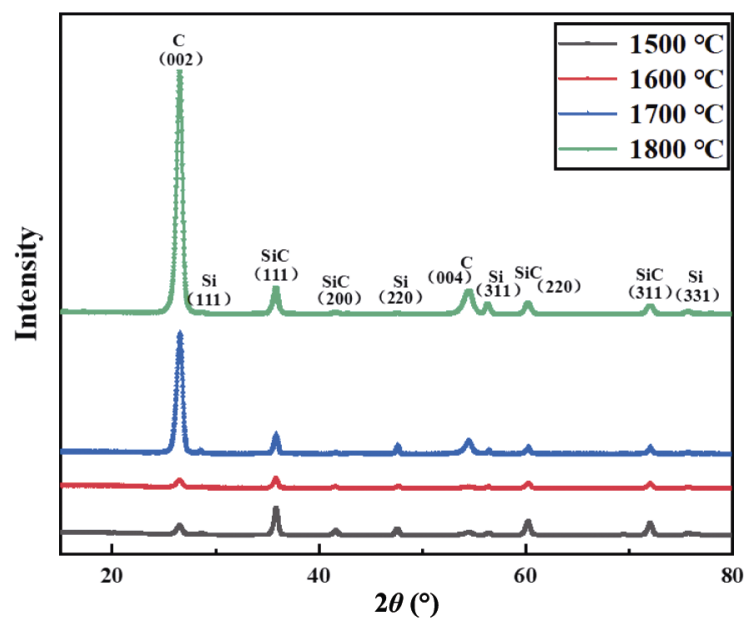

Fig. 8 XRD patterns of $\mathrm{C}_{\mathrm{pf}} / \mathrm{SiC}$ composites prepared at different siliconization temperatures. temperature, which blocked the permeability channels for molten $\mathrm{Si}$.

The thermal conductivity of the as-prepared composites showed the same trend as the density, suggesting the crucial impact of densification on heat transfer properties. Compared to $\mathrm{C} / \mathrm{SiC}$ composite prepared by $\mathrm{T} 300$, the $\mathrm{C}_{\mathrm{pf}} / \mathrm{SiC}$ composites possessed much better thermal conductivities in both the thickness and in-plane directions. In particular, the thermal conductivity in the in-plane direction was more than a dozen-fold higher than that of RMI C/SiC. As mentioned in Section 3.1, graphite crystallites with high orientation along the fiber axis direction greatly reduced the scattering of phonons, thereby improving the transfer efficiency. Compared to the preform prepared by plain weave in 
axial and radial directions, the preform fabricated by unidirectional fibers possessed more fibers per unit volume along specific directions. The heat transfer modes along different directions are presented in Fig. 9. Obviously, the heat flow was faster along the fiber direction with less loss. Along the thickness direction, the heat transfer efficiency greatly reduced due to the elevated interfacial thermal resistance (top right corner of Fig. 9).

In this work, because of the evaporation of large amounts of $\mathrm{Si}$ under high temperature, $\mathrm{SiC}_{\mathrm{w}}$ tended to grow at lower reaction temperatures $(1500,1600$, and $\left.1700{ }^{\circ} \mathrm{C}\right)$. As a result, $\mathrm{SiC}_{\mathrm{w}}$ did not only improve the densification of the composites but also filled some pores (Fig. 7(c)).

(a)

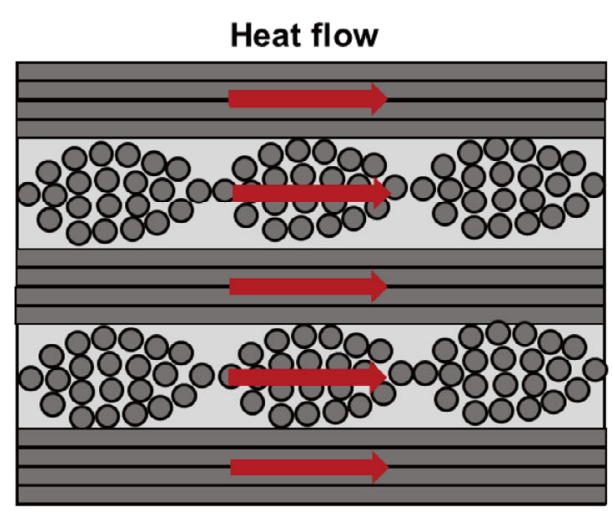

Fig. 9 Schematic diagram of heat transfer in different directions of the composites.
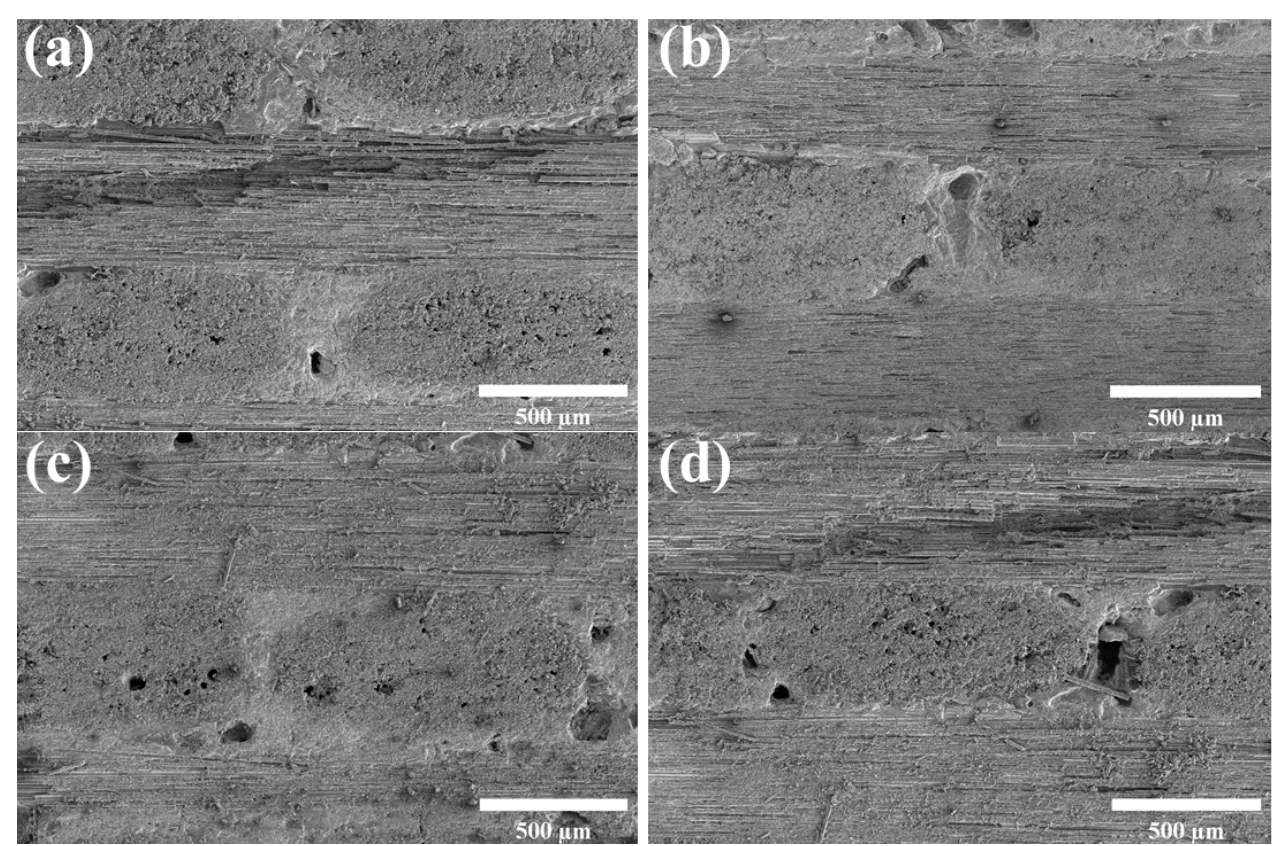

Fig. 10 Microstructures of $\mathrm{C}_{\mathrm{p} f} / \mathrm{SiC}$ composites obtained with different resin carbon contents: (a) 2C\#, (b) 4C\#, (c) 6C\#, and (d) 8C\#.

\subsubsection{Effect of different contents of resin carbon}

All samples were fabricated by the same RMI process at $1600{ }^{\circ} \mathrm{C}$ but at various resin carbon contents. The densities and thermal conductivities of composites obtained at different resin carbon contents are displayed in Table 5. In Section 3.3.1, $1600{ }^{\circ} \mathrm{C}$ was identified as the appropriate preparation temperature of $\mathrm{C}_{\mathrm{pf}} / \mathrm{SiC}$ composites. As a result, the increase in resin carbon content did not significantly affect the density and porosity, as seen from the microstructures of the composites. In Fig. 10, no obvious pores were observed, and the microstructures were relatively dense. Compared to thermal conductivities along the thickness direction

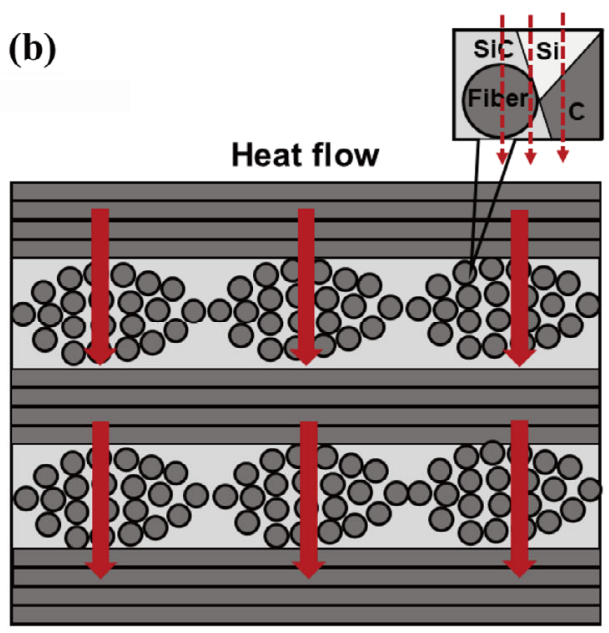


Table 5 Properties of $\mathrm{C}_{\mathrm{pf}} / \mathrm{SiC}$ composites prepared with different resin carbon contents

\begin{tabular}{|c|c|c|c|c|}
\hline \multirow{2}{*}{ Sample } & \multirow{2}{*}{$\begin{array}{l}\text { Density } \\
\left(\mathrm{g} / \mathrm{cm}^{3}\right)\end{array}$} & \multirow{2}{*}{$\begin{array}{l}\text { Porosity } \\
\text { (\%) }\end{array}$} & \multicolumn{2}{|c|}{ Thermal conductivity $(\mathrm{W} /(\mathrm{m} \cdot \mathrm{K}))$} \\
\hline & & & In-plane & Through-thickness \\
\hline $2 \mathrm{C} \#$ & 2.29 & 10.85 & 170.03 & 27.67 \\
\hline $4 \mathrm{C} \#$ & 2.31 & 11.63 & 175.79 & 34.66 \\
\hline $6 \mathrm{C} \#$ & 2.28 & 13.26 & 170.19 & 38.86 \\
\hline $8 \mathrm{C} \#$ & 2.21 & 13.88 & 162.50 & 18.45 \\
\hline
\end{tabular}

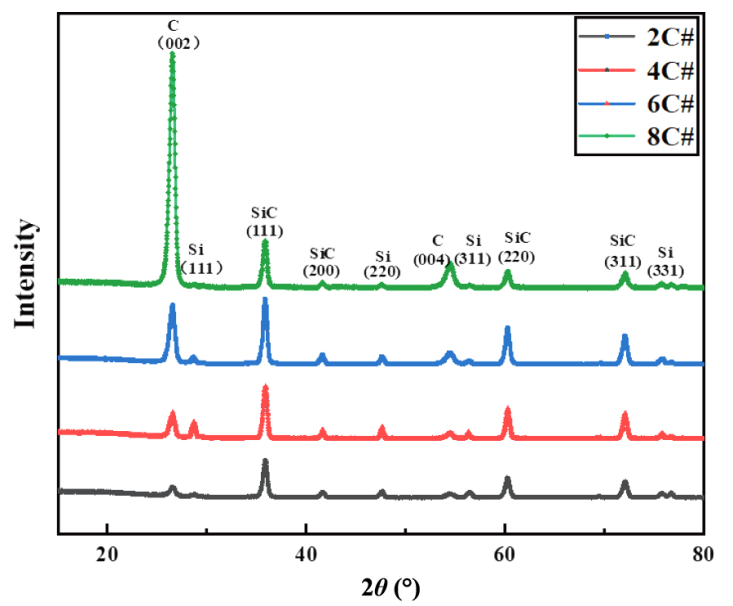

Fig. $11 \mathrm{XRD}$ patterns of $\mathrm{C}_{\mathrm{pf}} / \mathrm{SiC}$ composites prepared with different resin carbon contents.

(Table 5), the variation trend of the thermal conductivity along the in-plane direction was not obvious. Hence, the thermal conductivities along the in-plane direction were not significantly affected by the change in composite structures. Various resin carbon contents induced different phase compositions, thereby significantly affecting the thermal conductivities along the thickness direction of the composites. The phase constitution of the composites was analyzed by the XRD patterns (shown in Fig. 11), where the composites showed stronger $\mathrm{SiC}$ peaks compared to Fig. 8. Note that the amorphous type of resin carbon is more difficult to detect by XRD. However, the resin carbon remaining in the matrix would be graphitized at high temperature $\left(1600{ }^{\circ} \mathrm{C}\right)$ [38]. Consequently, the $\mathrm{C}$ peak in XRD became sharper and stronger. Additionally, BSE images of samples 4C\#, 6C\#, and 8C\# in Fig. 12 revealed the local content and distribution of carbon. In the magnified image of Fig. 12(c), massive and agglomerated carbon particles were surrounded by $\mathrm{SiC}$ matrix and some $\mathrm{Si}$, generating many grain boundaries.

As shown in Table 5, the thermal conductivities increased with carbon content and maximum value reached $38.86 \mathrm{~W} /(\mathrm{m} \cdot \mathrm{K})$. This could be attributed to the compact microstructure and high thermal conductivity of graphitized resin carbon. However, the thermal conductivity of $8 \mathrm{C} \#$ reduced to $18.45 \mathrm{~W} /(\mathrm{m} \cdot \mathrm{K})$ due to the interface thermal resistance generated by excess graphitized resin carbon and other phases ( $\mathrm{SiC}$ and $\mathrm{Si}$ ). On the other hand, the thermal conductivities along the in-plane direction were mainly generated by the pitch-based fibers, which were less impacted by the composite structures (Section 3.3.1). As a result, the thermal conductivities remained relatively stable.

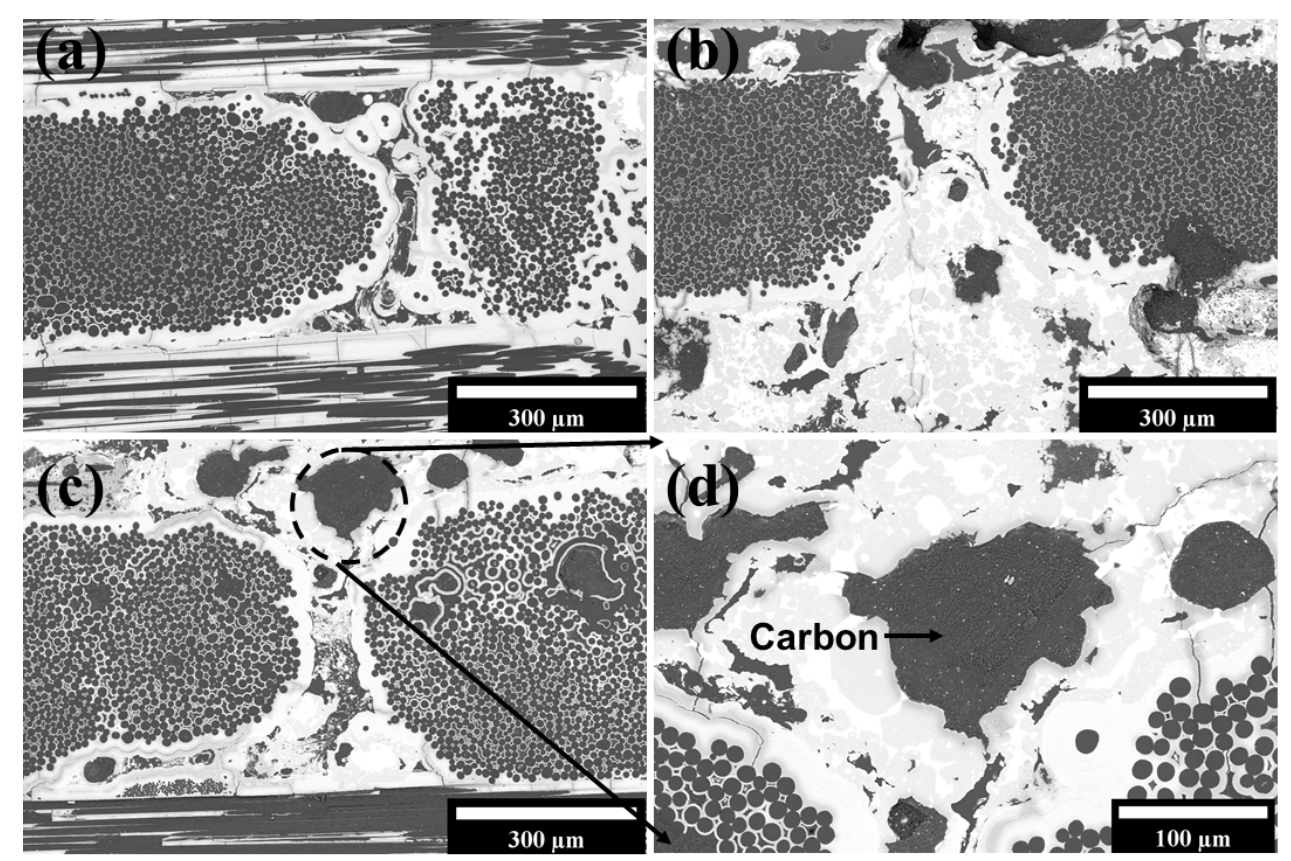

Fig. 12 BSE images of $\mathrm{C}_{\mathrm{pf}} / \mathrm{SiC}$ composites prepared with different resin carbon contents: (a) 4C\#, (b) 6C\#, and (c) 8C\#. 
Table 6 Bending strengths of $\mathrm{C}_{\mathrm{pf}} / \mathrm{SiC}$ composites prepared at different siliconization temperatures

\begin{tabular}{crrrr}
\hline Sample & \multicolumn{1}{c}{ T15\# } & \multicolumn{1}{c}{ T16\# } & \multicolumn{1}{c}{ T17\# } & $18 \#$ \\
\hline Bending strength $(\mathrm{MPa})$ & $178.54 \pm 6.88$ & $186.15 \pm 3.95$ & $178.26 \pm 6.74$ & $139.34 \pm 1.77$ \\
Bending modulus $(\mathrm{GPa})$ & $27.05 \pm 0.83$ & $28.71 \pm 3.13$ & $40.09 \pm 5.69$ & $11.76 \pm 4.22$ \\
\hline
\end{tabular}

\section{4 Bending strengths of $\mathrm{C}_{\mathrm{pf}} / \mathrm{SiC}$ composites}

\subsubsection{Effect of different siliconization temperatures}

The bending strengths and bending moduli of $\mathrm{C}_{\mathrm{pf}} / \mathrm{SiC}$ composites obtained at different reaction temperatures are listed in Table 6 . The bending strength of the composites at various siliconization temperatures was about $170 \mathrm{MPa}$, and composites with higher densities possessed better bending strengths. Compared to the bending strengths of traditional $\mathrm{C} / \mathrm{SiC}$ composites prepared by CVI process, $\mathrm{C}_{\mathrm{pf}} / \mathrm{SiC}$ composites showed lower but acceptable values. This could first be attributed to pitch-based carbon fibers. Microcrystalline graphite highly orientated along the fiber axis could provide elevated heat transfer properties but poor bending and compressive strengths since the graphite sheets were spaced far apart (Fig. 3). Second, the unidirectional fibers preform significantly affected the transverse bending strengths of the composites. For transverse strength of $0^{\circ} / 0^{\circ}$ composites, the fibers could not effectively bear the load transferred from the matrix in this direction [39]. Finally, the reactive melt of RMI process might damage the fibers, and the presence of residual $\mathrm{Si}$ and $\mathrm{C}$ would also reduce the mechanical properties of the composite due to cracks generated at the interface between the residual phase and matrix [22].

Photographs and microstructures of the fractured surfaces of samples T15\# and T18\# are depicted in Fig. 13. The fractured areas of the composites were large with layered failure mode, indicating the formation of composites with good toughness. The microstructures of the fractured samples showed that long fiber bundles were pulled out (Fig. 13). A pull-out effect [40] of the fibers can also be observed in Fig. 14(a). As mentioned above, pitch-based carbon fibers had distinct and highly orientated layered structures (Figs. 14(a) and 14(b)). Large amounts of fiber fragments were observed in Fig. 14(a), especially at high magnifications where the fractured surface of the fiber was not only flat but similar to a layered structure. Hence, the graphite layers of the fibers were pulled out from the inside through layer by layer mode under tensile and shear loads. This type of internal layered pull-out phenomenon is typical for pitch carbon fibers.

On the other hand, $\mathrm{SiC}_{\mathrm{w}}$ played an important role in strengthening and toughening of composites, especially in terms of toughening [41,42]. Here, the main toughening mechanisms of $\mathrm{SiC}_{\mathrm{w}}$ were based on crack deflection, crack bridging, and whisker pull-out. First, the crack propagating in the matrix was deflected upon contact with $\mathrm{SiC}_{\mathrm{w}}$ due to the mismatch in the elastic modulus between $\mathrm{SiC}_{\mathrm{w}}$ and $\mathrm{SiC}$ matrix [43]. In turn, crack deflection could change the propagation path of the crack or make the crack branched, thereby absorbing the fracture energy and resulting in cracks no longer
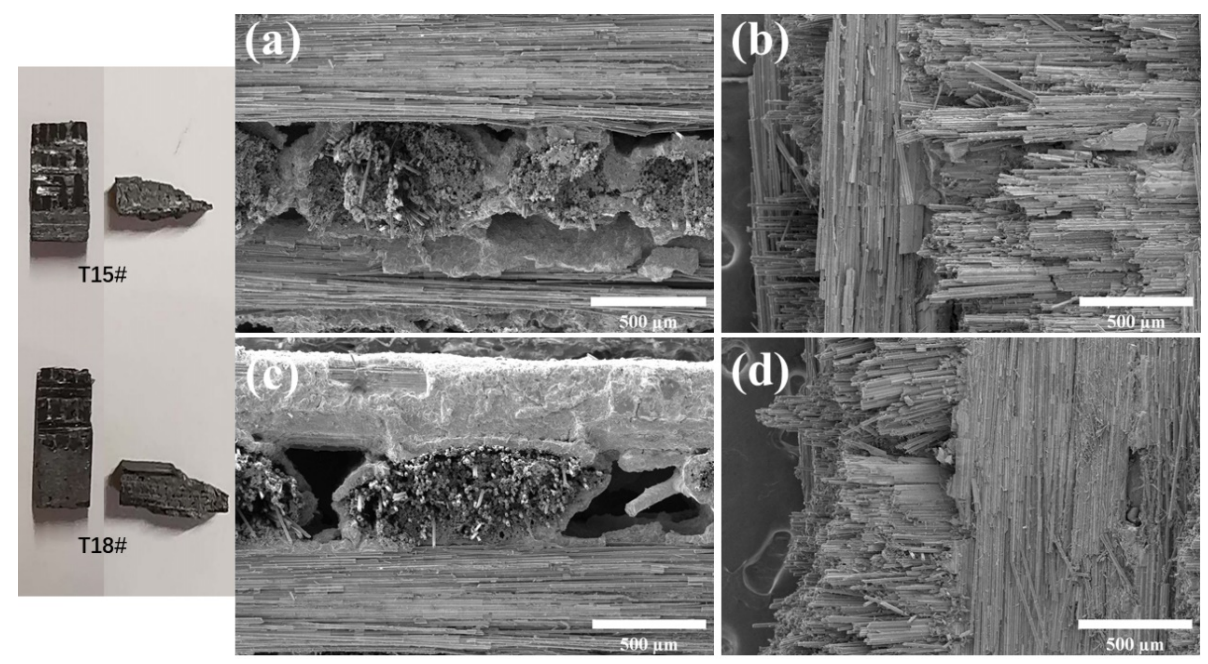

Fig. 13 Photographs and microstructures of the fractured surfaces of samples T15\# and T18\#. 

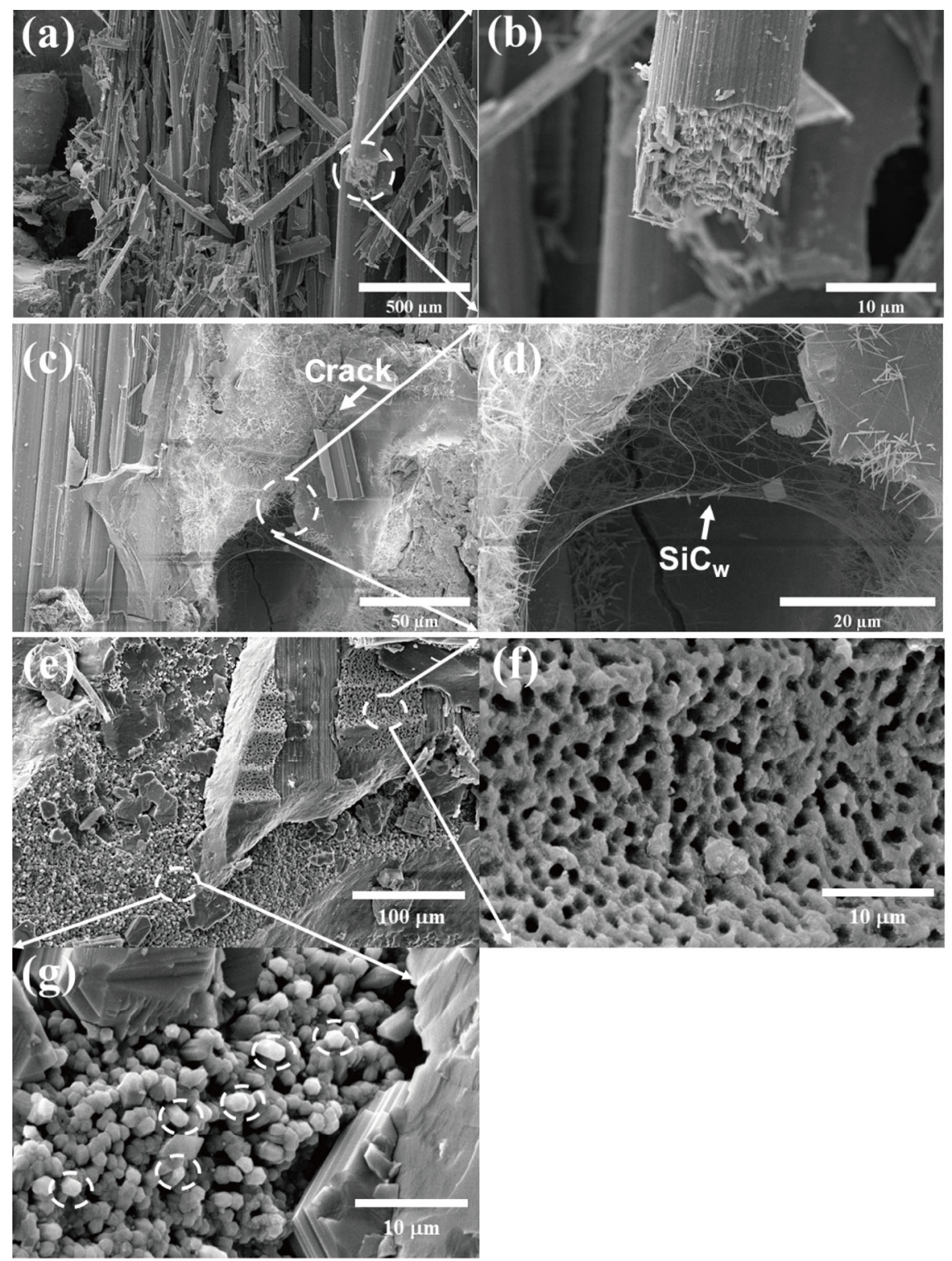

Fig. 14 Microstructures of fractured fibers and $\mathrm{SiC}_{\mathrm{w}}$.

perpendicular to the stress. Hence, the crack can further be expanded by only increasing the strength of the stress at the crack tip. In turn, this process released stress concentration at the crack tip, inhibiting the crack propagation in the composites [43]. Second, crack bridging occurred behind the crack front where the bridging ligaments were connected to the crack faces. By adding extra pressure during the crack opening, $\mathrm{SiC}_{\mathrm{w}}$ decreased the stress intensity near the crack tip, thereby toughening the composites [44]. As shown in Figs. 14(c) and 14(d), large amounts of $\mathrm{SiC}_{\mathrm{w}}$ were distributed on both sides of the crack. Lastly, plenty of pulled-out $\mathrm{SiC}_{\mathrm{w}}$ covered by $\mathrm{SiC}$ matrix and holes left after pull-out were clearly observed in Figs. 14(e)-14(g). Due to the high tensile strength of whiskers, they are difficult to break. When the load was transferred from the matrix to the whiskers, and the shear stress generated on the interface between them reached the shear strength of the interface, the whiskers pulled out from the matrix [45]. Extra energy would be consumed when whiskers are pulled out.

\subsubsection{Effect of different contents of resin carbon}

The bending strengths and moduli of $\mathrm{C}_{\mathrm{p} f} / \mathrm{SiC}$ composites prepared with different resin carbon contents are listed in Table 7. The average bending strength improved by $25 \%$ compared to the values listed in Table 6 , and the optimal value reached $244.62 \pm 3.07 \mathrm{MPa}$. During RMI process, residual $\mathrm{Si}$ remaining in the $\mathrm{SiC}$ matrix reduced the mechanical properties due to the unequal stress generated by different coefficients of thermal expansion. 
Table 7 Bending strengths of $\mathrm{C}_{\mathrm{pf}} / \mathrm{SiC}$ composites prepared with different resin carbon contents

\begin{tabular}{ccccc}
\hline Sample & $2 \mathrm{C} \#$ & $4 \mathrm{C} \#$ & $6 \mathrm{C \#}$ & $8 \mathrm{C} \#$ \\
\hline Bending strength (MPa) & $176.15 \pm 13.62$ & $195.03 \pm 7.98$ & $244.62 \pm 3.07$ & $233.57 \pm 10.33$ \\
Bending modulus (GPa) & $34.39 \pm 1.33$ & $36.66 \pm 5.95$ & $40.32 \pm 3.21$ & $38.09 \pm 5.91$ \\
\hline
\end{tabular}

Hence, sufficient carbon sources were beneficial to the RMI process with less residual $\mathrm{Si}$.

Photographs and microstructures of $\mathrm{C}_{\mathrm{p} f} \mathrm{SiC}$ composites prepared with different resin carbon contents are presented in Fig. 15. The holes are left after fiber pull-out and abundant $\mathrm{SiC}_{\mathrm{w}}$ can be clearly observed in Figs. 15(a) and 15(b), respectively. This indicated the ductile fracture of the composites. Note that the same fracture behavior and the toughening mechanism by $\mathrm{SiC}_{\mathrm{w}}$ were discussed in Section 3.4.1.
The thermal conductivities and bending strengths of recently reported fiber-reinforced ceramic matrix composites in comparison with materials prepared in this study are summarized in Table 8 . Composites prepared herein showed excellent heat transfer performance and favorable bending strengths. At present, there is limited research on pitch-based fiber reinforced ceramic matrix composites, but this comparison shows great potential of these materials, which deserve to be studied further.
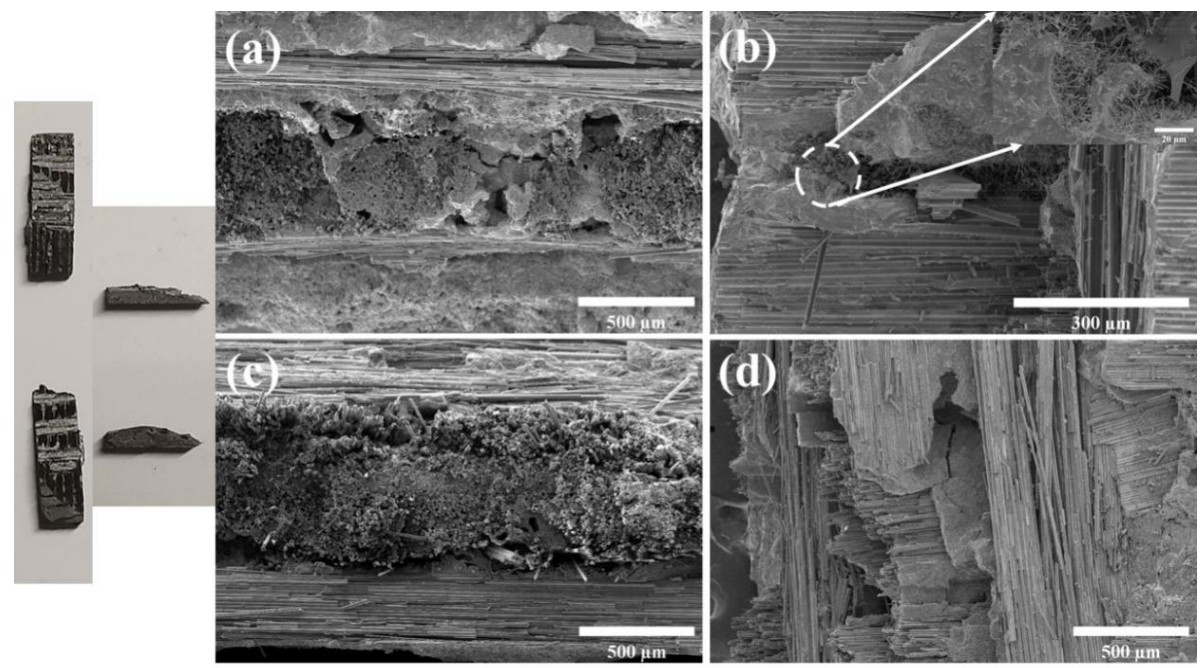

Fig. 15 Photographs and microstructures of fractured surfaces of samples 4C\# and 8C\#.

Table 8 Thermal conductivities and bending strengths of recently reported fiber-reinforced ceramic matrix composites in comparison with the materials prepared in this study

\begin{tabular}{|c|c|c|c|c|}
\hline Ref. & Composite & Method & Thermal conductivity $(\mathrm{W} /(\mathrm{m} \cdot \mathrm{K}))$ & Bending strength (MPa) \\
\hline [8] & $\mathrm{C} / \mathrm{SiC}-\mathrm{CNT}$ & CVI & $22.36 \perp$ & $395.92 \pm 19.01$ \\
\hline [12] & $\mathrm{C} / \mathrm{SiC}-\mathrm{CNT}$ & CVI & $32.70 \pm 0.72 \perp$ & - \\
\hline [46] & $\mathrm{C} / \mathrm{SiC}-\mathrm{SiC}_{\mathrm{nw}}$ & PIP & $3.30 \perp, 8.18 / /$ & $336 \pm 16$ \\
\hline [22] & Diamond-C/SiC & RMI & $14.68 \perp$ & 309.01 \\
\hline [47] & Diamond- $\mathrm{C} / \mathrm{SiC}$ & RMI & $9-10 \perp$ & 365 \\
\hline [9] & $\mathrm{C} / \mathrm{SiC}-\mathrm{CNT}$ & PIP & $16.8 \perp$ & 248.62 \\
\hline [48] & $\mathrm{C} / \mathrm{SiC}-\mathrm{Ti}_{3} \mathrm{SiC}_{2}$ & RMI & $12.6 \perp$ & $539 \pm 39$ \\
\hline [16] & $\mathrm{C} / \mathrm{SiC}$ (pitch-based fibers) & PIP & - & 150 \\
\hline [40] & $\mathrm{C} / \mathrm{SiC}$ & PIP & $35 \perp, 150 / /$ & 285 \\
\hline This work & $\mathrm{C} / \mathrm{SiC}$ & RMI & $39.59 \perp, 203.00 / /$ & $244.62 \pm 3.07$ \\
\hline [6] & $\mathrm{SiC} / \mathrm{SiC}$ & CVI & $26.7 \perp$ & $482.00 \pm 36$ \\
\hline [49] & $\mathrm{SiC} / \mathrm{SiC}$ & PIP & $14.3 \perp$ & $468.16 \pm 16$ \\
\hline [39] & $\mathrm{C} / \mathrm{ZrB}_{2}-\mathrm{SiC}$ (pitch-based fibers) & PIP & - & $260 \pm 20$ \\
\hline [50] & $\mathrm{C} / \mathrm{ZrB}_{2}-\mathrm{SiC}$ (short pitch-based fibers) & Hot-press & $48.3-104.7 \perp$ & - \\
\hline [51] & $\mathrm{C} / \mathrm{HfB}_{2}-\mathrm{SiC}$ (short pitch-based fibers) & Hot-press & $93.8 \perp$ & - \\
\hline
\end{tabular}




\section{Conclusions}

$\mathrm{C}_{\mathrm{pf}} / \mathrm{SiC}$ composites were successfully fabricated by RMI method by controlling the reaction temperature and resin carbon content. The thermal conductivities and bending strengths of the as-obtained composites under different preparation conditions were studied and results were discussed. The following conclusions can be drawn:

$\mathrm{SiC}$ whiskers were formed during RMI process through a VS mechanism. Growth mechanism at different siliconization temperatures was investigated by the Gibbs free energy of the reactions. The presence of $\mathrm{SiC}_{\mathrm{w}}$ played an important role in toughening of $\mathrm{C}_{\mathrm{p} f} / \mathrm{SiC}$ composites.

The increase in reaction temperature of RMI process first led to a rising trend of the thermal conductivity along the in-plane and thickness directions, followed by a decline. At $1600{ }^{\circ} \mathrm{C}$, the thermal conductivities along the in-plane and thickness directions were recorded as 203.00 and $39.59 \mathrm{~W} /(\mathrm{m} \cdot \mathrm{K})$, respectively. The bending strength was $186.15 \pm 3.95 \mathrm{MPa}$.

The increase in resin carbon content before RMI process led to the formation of more $\mathrm{SiC}$ matrix. The thermal conductivities along the in-plane and thickness directions remained stable at 175.79 and $38.86 \mathrm{~W} /(\mathrm{m} \cdot \mathrm{K})$, respectively. Also, the optimal bending strength improved to $244.62 \pm 3.07 \mathrm{MPa}$.

\section{Acknowledgements}

This work is supported by the National Key R\&D Program of China (No. 2018YFB1106600), the National Natural Science Foundation of China (Nos. 51602257, 92060202, 51872229, and 51972269), the State Key Laboratory of Advanced Technology for Materials Synthesis and Processing (Wuhan University of Technology, No. 2021-KF-10), the Creative Research Foundation of the Science and Technology on Thermostructural Composite Materials Laboratory (No. JCKYS2020607001), and the Shaanxi Province Foundation for Natural Science (No. 2020JQ-169).

\section{References}

[1] Krenkel W. Carbon fiber reinforced CMC for high-performance structures. Int J Appl Ceram Technol 2004, 1: 188-200.

[2] Krenkel W, Berndt F. C/C-SiC composites for space applications and advanced friction systems. Mater Sci Eng A: Struct 2005, 412: 177-181.
[3] Kumar S, Kumar A, Sampath K, et al. Fabrication and erosion studies of C-SiC composite Jet Vanes in solid rocket motor exhaust. J Eur Ceram Soc 2011, 31: 2425-2431.

[4] Lamouroux F, Bertrand S, Pailler R, et al. Oxidation-resistant carbon-fiber-reinforced ceramic-matrix composites. Compos Sci Technol 1999, 59: 1073-1085.

[5] Dong Y, Ren K, Lu YH, et al. High-entropy environmental barrier coating for the ceramic matrix composites. $J$ Eur Ceram Soc 2019, 39: 2574-2579.

[6] Tao PF, Wang YG. Improved thermal conductivity of silicon carbide fibers-reinforced silicon carbide matrix composites by chemical vapor infiltration method. Ceram Int 2019, 45: 2207-2212.

[7] Zhao ZF, Liu YS, Feng W, et al. Improvement on the thermal conductivity of diamond/CVI-SiC composites using large diamond particles. Diam Relat Mater 2017, 74: 1-8.

[8] Cao LY, Liu YS, Zhang YH, et al. Enhancing thermal conductivity of $\mathrm{C} / \mathrm{SiC}$ composites containing heat transfer channels. J Eur Ceram Soc 2020, 40: 3520-3527.

[9] Chen SC, Feng YY, Qin MM, et al. Improving thermal conductivity in the through-thickness direction of carbon fibre/SiC composites by growing vertically aligned carbon nanotubes. Carbon 2017, 116: 84-93.

[10] Yang JS, Sprengard J, Ju LC, et al. Three-dimensionallinked carbon fiber-carbon nanotube hybrid structure for enhancing thermal conductivity of silicon carbonitride matrix composites. Carbon 2016, 108: 38-46.

[11] Feng W, Zhang LT, Liu YS, et al. Fabrication of $\mathrm{SiC}_{\mathrm{f}}-\mathrm{CNTs} / \mathrm{SiC}$ composites with high thermal conductivity by vacuum filtration combined with CVI. Mater Sci Eng: A 2016, 662: 506-510.

[12] Zhang YH, Liu YS, Cao YJ, et al. Effect of initial density on thermal conductivity of new micro-pipeline heat conduction C/SiC composites. J Am Ceram Soc 2021, 104: 645-653.

[13] Rahaman MSA, Ismail AF, Mustafa A. A review of heat treatment on polyacrylonitrile fiber. Polym Degrad Stab 2007, 92: 1421-1432.

[14] Huang XS. Fabrication and properties of carbon fibers. Materials 2009, 2: 2369-2403.

[15] El-Hage Y, Hind S, Robitaille F. Thermal conductivity of textile reinforcements for composites. J Text Fibrous Mater 2018, 1, https://doi.org/10.1177/2515221117751154.

[16] Odeshi AG, Mucha H, Wielage B. Manufacture and characterisation of a low cost carbon fibre reinforced $\mathrm{C} / \mathrm{SiC}$ dual matrix composite. Carbon 2006, 44: 1994-2001.

[17] Liu JC, Chen XJ, Liang DC, et al. Development of pitch-based carbon fibers: A review. Energy Sources A: Recovery Util Environ Eff 2020, https://doi.org/10.1080/ 15567036.2020.1806952.

[18] Nysten B, Piraux L, Issi JP. Thermal conductivity of pitch-derived fibres. J Phys D: Appl Phys 1985, 18: 13071310.

[19] Servadei F, Zoli L, Galizia P, et al. Development of UHTCMCs via water based $\mathrm{ZrB}_{2}$ powder slurry infiltration 
and polymer infiltration and pyrolysis. $J$ Eur Ceram Soc 2020, 40: 5076-5084.

[20] Mainzer B, Lin CR, Jemmali R, et al. Characterization and application of a novel low viscosity polysilazane for the manufacture of $\mathrm{C}$ - and $\mathrm{SiC}$-fiber reinforced $\mathrm{SiCN}$ ceramic matrix composites by PIP process. J Eur Ceram Soc 2019, 39: 212-221.

[21] Patel M, Saurabh K, Prasad VVB, et al. High temperature $\mathrm{C} / \mathrm{C}-\mathrm{SiC}$ composite by liquid silicon infiltration: A literature review. Bull Mater Sci 2012, 35: 63-73.

[22] Li JX, Liu YS, Chen C, et al. Effect of diamond content on microstructure and properties of $\mathrm{C} / \mathrm{SiC}$-diamond composites. Diam Relat Mater 2020, 107: 107902.

[23] Zhong Q, Zhang XY, Dong SM, et al. Reactive melt infiltrated $\mathrm{C}_{\mathrm{f}} / \mathrm{SiC}$ composites with robust matrix derived from novel engineered pyrolytic carbon structure. Ceram Int 2017, 43: 5832-5836.

[24] Iwashita N, Park CR, Fujimoto H, et al. Specification for a standard procedure of X-ray diffraction measurements on carbon materials. Carbon 2004, 42: 701-714.

[25] Zickler GA, Smarsly B, Gierlinger N, et al. A reconsideration of the relationship between the crystallite size La of carbons determined by X-ray diffraction and Raman spectroscopy. Carbon 2006, 44: 3239-3246.

[26] Pradere C, Batsale JC, Goyhénèche JM, et al. Thermal properties of carbon fibers at very high temperature. Carbon 2009, 47: 737-743.

[27] Patterson AL. The Scherrer formula for X-ray particle size determination. Phys Rev 1939, 56: 978-982.

[28] Cuesta A, Dhamelincourt P, Laureyns J, et al. Raman microprobe studies on carbon materials. Carbon 1994, 32: 1523-1532.

[29] Ferrari AC, Meyer JC, Scardaci V, et al. Raman spectrum of graphene and graphene layers. Phys Rev Lett 2006, 97 : 187401.

[30] Tuinstra F, Koenig JL. Raman spectrum of graphite. $J$ Chem Phys 1970, 53: 1126-1130.

[31] Bennett SC, Johnson DJ, Murray R. Structural characterisation of a high-modulus carbon fibre by high-resolution electron microscopy and electron diffraction. Carbon 1976, 14: 117-122.

[32] Dai JX, Sha JJ, Zhang ZF, et al. Synthesis of high crystalline beta $\mathrm{SiC}$ nanowires on a large scale without catalyst. Ceram Int 2015, 41: 9637-9641.

[33] Li YW, Wang QH, Fan HB, et al. Synthesis of silicon carbide whiskers using reactive graphite as template. Ceram Int 2014, 40: 1481-1488.

[34] Wei J, Li KZ, Li HJ, et al. Large-scale synthesis and photoluminescence properties of hexagonal-shaped $\mathrm{SiC}$ nanowires. J Alloys Compd 2008, 462: 271-274.

[35] Chen JP, Song G, Liu Z, et al. Preparation of SiC whiskers using graphene and rice husk ash and its photocatalytic property. J Alloys Compd 2020, 833: 155072.

[36] Larpkiattaworn S, Ngernchuklin P, Khongwong W, et al. The influence of reaction parameters on the free $\mathrm{Si}$ and $\mathrm{C}$ contents in the synthesis of nano-sized SiC. Ceram Int 2006, 32: 899-904.

[37] Chiang YM, Messner RP, Terwilliger CD, et al. Reactionformed silicon carbide. Mater Sci Eng: A 1991, 144: 63-74.

[38] Tzeng SS, Chr YG. Evolution of microstructure and properties of phenolic resin-based carbon/carbon composites during pyrolysis. Mater Chem Phys 2002, 73: 162-169.

[39] Sciti D, Zoli L, Vinci A, et al. Effect of PAN-based and pitch-based carbon fibres on microstructure and properties of continuous $\mathrm{C}_{\mathrm{f}} / \mathrm{ZrB}_{2}-\mathrm{SiC}$ UHTCMCs. J Eur Ceram Soc 2021, 41: 3045-3050.

[40] Reimer T, Petkov I, Koch D, et al. Fabrication and characterization of $\mathrm{C} / \mathrm{C}-\mathrm{SiC}$ material made with pitch-based carbon fibers. In: Processing and Properties of Advanced Ceramics and Composites VII. Mahmoud MM, Bhalla A, Bansal NP, et al. Eds. John Wiley \& Sons, Inc., 2015: 277-293.

[41] Mei H, Wang HW, Ding H, et al. Strength and toughness improvement in a $\mathrm{C} / \mathrm{SiC}$ composite reinforced with slurry-prone SiC whiskers. Ceram Int 2014, 40: 14099 14104.

[42] Oh BJ, Lee YJ, Choi DJ, et al. Fabrication of carbon/silicon carbide composites by isothermal chemical vapor infiltration, using the in situ whisker-growing and matrix-filling process. $J$ Am Ceram Soc 2001, 84: 245-247.

[43] Jiang X, Chen Y, Sun XW, et al. Mechanical property improvement and microstructure observation of $\mathrm{SiC}_{\mathrm{w}}-\mathrm{AlN}$ composites. J Eur Ceram Soc 1999, 19: 2033-2038.

[44] Qin QH. 1-Introduction to the composite and its toughening mechanisms. In: Toughening Mechanisms in Composite Materials. Amsterdam (the Netherlands): Elsevier, 2015: 1-32.

[45] Deng JX. Effect of thermal residual stress on the high temperature toughening behaviour of $\mathrm{TiB}_{2} / \mathrm{SiCw}$ composites. J Mater Process Technol 2000, 98: 292-298.

[46] Hu JB, Dong SM, Wu B, et al. Mechanical and thermal properties of $\mathrm{C}_{\mathrm{f}} / \mathrm{SiC}$ composites reinforced with carbon nanotube grown in situ. Ceram Int 2013, 39: 3387-3391.

[47] Li JX, Liu YS, Nan BY, et al. Microstructure and properties of $\mathrm{C} / \mathrm{SiC}$-diamond composites prepared by the combination of CVI and RMI. Adv Eng Mater 2019, 21: 1800765

[48] Fan XM, Yin XW, Cao XY, et al. Improvement of the mechanical and thermophysical properties of $\mathrm{C} / \mathrm{SiC}$ composites fabricated by liquid silicon infiltration. Compos Sci Technol 2015, 115: 21-27.

[49] Feng W, Zhang LT, Liu YS, et al. Thermal and mechanical properties of $\mathrm{SiC} / \mathrm{SiC}-\mathrm{CNTs}$ composites fabricated by CVI combined with electrophoretic deposition. Mater Sci Eng: A 2015, 626: 500-504.

[50] Guo SQ. Thermal and electrical properties of hot-pressed short pitch-based carbon fiber-reinforced $\mathrm{ZrB}_{2}-\mathrm{SiC}$ matrix composites. Ceram Int 2013, 39: 5733-5740.

[51] Guo SQ, Naito K, Kagawa Y. Mechanical and physical behaviors of short pitch-based carbon fiber-reinforced $\mathrm{HfB}_{2}-\mathrm{SiC}$ matrix composites. Ceram Int 2013, 39: 15671574. 
Open Access This article is licensed under a Creative Commons Attribution 4.0 International License, which permits use, sharing, adaptation, distribution and reproduction in any medium or format, as long as you give appropriate credit to the original author(s) and the source, provide a link to the Creative Commons licence, and indicate if changes were made.

The images or other third party material in this article are included in the article's Creative Commons licence, unless indicated otherwise in a credit line to the material. If material is not included in the article's Creative Commons licence and your intended use is not permitted by statutory regulation or exceeds the permitted use, you will need to obtain permission directly from the copyright holder.

To view a copy of this licence, visit http://creativecommons. org/licenses/by/4.0/. 